\title{
Awareness Regarding Primary Eye Care Among Primary Healthcare Workers of Pakistan: a Way to Revitalize Health for All!
}

\author{
Noor-ur-Rehman ${ }^{1}$, Hina Sharif ${ }^{2}$ \\ ${ }^{1-2}$ Department of Ophthalmology, Al-Shifa Trust and Eye Hospital, Karachi
}

\begin{abstract}
Purpose: To assess awareness regarding Primary Eye Care among (primary healthcare workers) PHCWs and also intended to identify its determinants.

Study Design: Descriptive cross-sectional study.

Place and Duration of Study: All primary healthcare facilities of Tehsil Kallar Syedan, from October 2019 to December 2019.

Methods: The calculated sample size was 115. Data was collected from primary health care workers (PHCWs). Data was collected through a structured questionnaire with both open-ended and close-ended questions. Questions were made using simple language and were also translated in Urdu. Questionnaire was adapted from two articles and some questions were made after reading the components of National Programme for Prevention and Control of Blindness (Punjab, Pakistan).Chi-square test of independence was used for finding associations.
\end{abstract}

Results: Fifty-four percent PHCWs had poor awareness regarding primary eye care. Majority of the PHCWs, $\mathrm{N}=64(55.7 \%)$ identified just the names of common eye diseases. Cataract was identified with correct treatment by $88 \%$ primary healthcare workers. Age, education, designation were significantly associated with awareness of PHCWs.

Conclusion: The study concluded that more than half of PHCWs had low awareness regarding PEC. All of them mentioned that there was a need of improving and refreshing their knowledge related to primary eye care. This will definitely help to reduce pressure on secondary and tertiary healthcare workers.

Key Words: Primary eye care, Primary healthcare workers, Primary healthcare facilities, Pakistan.

How to Cite this Article: Rehman N, Sharif H. Awareness Regarding Primary Eye Care Among Primary Healthcare Workers of Pakistan: a Way to Revitalize Health for All! Pak J Ophthalmol. 2021, 37 (2): 161-167.

Doi: http://doi.org/10.36351/pjo.v37i2.1146

\section{INTRODUCTION}

Primary eye care (PEC) is an essential part of primary healthcare (PHC), which involves methods and

Correspondence: Hina Sharif

Department of Ophthalmology, Al-Shifa Trust and Eye Hospital, Karachi

Email: pcc4u@hotmail.com

Received: October 15, 2020

Accepted: February 1, 2021 techniques for promotion of healthy eyes and provision of PEC to the community and involves primary healthcare workers. Pakistan has huge burden of eye diseases for which primary eye care is an important element of primary health care.

The concept of primary eye care (PEC) was born as a consequence of the Alma Ata meeting in 1978, which highlighted the tenets of primary health care (PHC). ${ }^{1}$ WHO reports on universal eye health (Global Action Plan 2014-2019) states that more than 2.2 billion people have vision impairment globally. Of those at least 1 billion people have preventable vision 
impairment. ${ }^{2}$ The basic elements of PHC include water supply, sanitation, nutrition, Immunization against infectious diseases, Maternal and child health, treatment of common diseases, prevention and control of common diseases and injuries, provision of adequate drugs and Health Education. ${ }^{3}$

Majority of the people with treatable blindness cannot access eye care services because of lack of awareness regarding available services. ${ }^{4}$ The primary factors which influence the uptake of eye care services are availability, accessibility and affordability. ${ }^{5}$ Primary Health Care Workers (PHCWs) are the main personnel to link the chain between primary health care facilities and rural community. Early detection of common diseases and timely referral can reduce the burden of avoidable blindness. This can be achieved if PHCWs are properly equipped with adequate knowledge, tools and supported by a good referral system including regular interaction and coordinated team work between full time eye workers, integrated eye workers and community eye worker.,

Pakistan has a strong structure of primary healthcare in the form of basic health units (BHUs) and rural health centers (RHCs). Lady health workers (LHWs), lady health visitors (LHVs) and lady health supervisors (LHSs) are the backbone of this globally acknowledged structure. This was fundamentally constructed to shift burden of higher tiers of healthcare (secondary and tertiary) towards primary; so that people can have awareness and treatment at their doorsteps. Pakistan has also huge burden of eye diseases therefore, primary eye care always remains as an important element of primary health care. This study aimed to assess awareness regarding PEC among PHCWs and also intended to identify its determinants.

\section{METHODS}

A quantitative cross-sectional study was conducted within the duration of three months starting from October 2019 to December 2019 in all primary healthcare facilities of Tehsil Kallar Syedan, Pakistan. The study population was PHCWs including Lady Healthcare Workers (LHW), Lady Healthcare Visitors (LHV) and Lady Healthcare Supervisors (LHS). The sample size was calculated with the help of an online software Open-Epi by taking population size of LHW, LHV and LHS to be 150, prevalence taken was $50 \%$ and $5 \%$ margin of error. The calculated sample size was 115. The sampling frame of all PHCWs was obtained and data was collected from LHW, LHV and
LHS. Data was collected through a structured questionnaire with both open-ended and close-ended questions. Questions were made using simple language and were also translated in Urdu. The validity of questionnaire was checked before starting data collection by performing a pilot study on LHW. Questionnaire was adapted from two articles: Knowhow of Primary eye care among Health Extension Workers in Southern Ethopia and Awareness of eye health and diseases among the population of the Hilly region of $\mathrm{Nepal}^{8}$ and some questions were made after reading the components of National Programme for Prevention and Control of Blindness (Punjab, Pakistan). ${ }^{3}$ Validity was checked for English version with the help of subject specialist. Later on, after translation into Urdu, validity was rechecked to ensure same meaning of translated words. Reliability was checked with the help of Chronbach's Alpha and it was 0.69 .

Data was analyzed by using statistical software SPSS Version-20.0. Qualitative variables were given numbers and percentages. Scale of awareness was computed and categorized into poor and good awareness by taking median. Chi-square test of independence was used for finding association between outcome variable and independent variable. This test was applied on all independent variables and outcome variables. A significance level of 5\% was used for all inferential statistics. The study was conducted after approval from Institutional Review Board (IRB) of Al-Shifa trust eye hospital. All the respondents were included after taking verbal consent from them.

\section{RESULTS}

Mean age of the participants $44 \pm 7.85$ years. Majority of the respondents (86\%) were Lady Healthcare Workers (LHW's).

Table1: Sociodemographic Characteristics.

\begin{tabular}{ccc}
\hline Demographics & Frequency(n) & Percentage (\%) \\
\hline Education (years) & & \\
8 & 15 & 13 \\
10 & 69 & 60 \\
12 & 25 & 21.7 \\
14 & 5 & 4.3 \\
Marital Status & & 6.1 \\
$\quad$ Single & 7 & 93.9 \\
$\quad$ Married & 108 & \\
Experience (years) & & 40.9 \\
5- 15 & 47 &
\end{tabular}




\begin{tabular}{|c|c|c|}
\hline $16-25$ & 66 & 57.4 \\
\hline$>25$ & 2 & 1.7 \\
\hline \multicolumn{3}{|l|}{ Currently working as } \\
\hline $\begin{array}{l}\text { Lady Healthcare } \\
\text { Supervisor }\end{array}$ & 8 & 7 \\
\hline $\begin{array}{l}\text { Lady Healthcare } \\
\text { Worker }\end{array}$ & 99 & 86.1 \\
\hline Lady Healthcare Visitor & 8 & 7 \\
\hline \multicolumn{3}{|l|}{ Previous eye training } \\
\hline Yes & 103 & 89.6 \\
\hline No & 12 & 10.4 \\
\hline \multicolumn{3}{|l|}{ No. of training } \\
\hline Never & 10 & 8.7 \\
\hline Once & 21 & 18.3 \\
\hline Twice & 35 & 30.4 \\
\hline $3-4$ times & 48 & 41.7 \\
\hline \multicolumn{3}{|l|}{$\begin{array}{l}\text { Eye patients seen in a } \\
\text { month }\end{array}$} \\
\hline $1-5$ & 70 & 60.9 \\
\hline $6-10$ & 29 & 25.2 \\
\hline$>11$ & 11 & 9.6 \\
\hline
\end{tabular}

Majority of the PHCWs, $\mathrm{N}=64$ (55.7\%) identified just the names of common eye diseases (Cataract, Red Eye, Glaucoma). Further information regarding their knowledge of eye diseases in mentioned in graph 1.

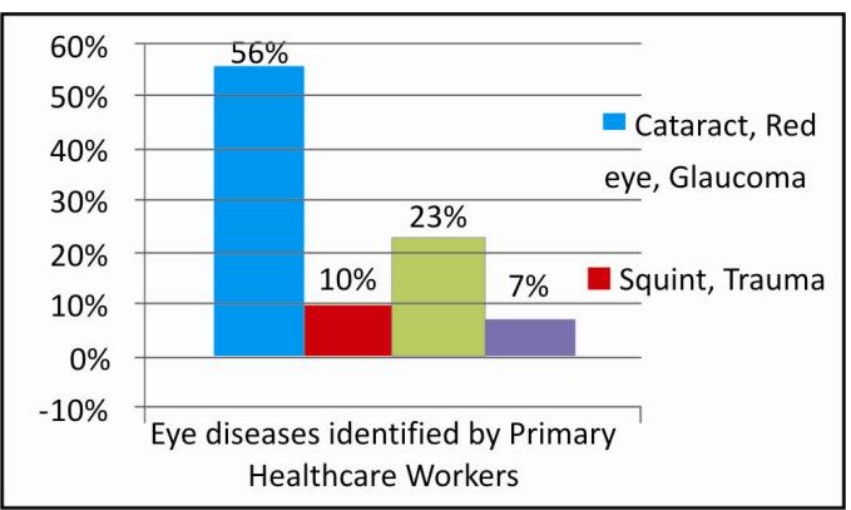

Graph 1: Eye diseases identified by Primary Healthcare Workers (PHCW's).

Basic knowledge about the eye disease is depicted in table 2 .

Table 2: Awareness about Primary Eye Care among PHCWs.

\begin{tabular}{lcc}
\hline Variables & $\begin{array}{c}\text { Frequency } \\
(\mathbf{n})\end{array}$ & $\begin{array}{c}\text { Percentage } \\
(\mathbf{\%})\end{array}$ \\
\hline PEC definition: & & \\
$\begin{array}{l}\text { Maintain personal and ocular } \\
\text { hygiene }\end{array}$ & 53 & 46.1 \\
Correctly defined & 62 & 53.9 \\
Not correctly defined & & \\
Can identify and refer the & &
\end{tabular}

common eye diseases

Yes $\quad 52 \quad 45.2$

No $\quad 63 \quad 54.8$

Can you measure Visual Acuity?

Yes

$113 \quad 98.3$

No $\quad 2 \quad 1.7$

Is PEC essential part of PHC?

$\begin{array}{lrr}\text { Yes } & 106 & 92.2\end{array}$

No $\quad 4 \quad 3.5$

I don't know $\quad 5 \quad 4.3$

When should eye-specialist be visited?

In case of any eye problem $\quad 28 \quad 24.3$

$\begin{array}{lll}\text { Once a year } & 57 & 49.6\end{array}$

Twice a year $\quad 30 \quad 26.1$

What does white pupillary reflex show?

Night blindness $\quad 7 \quad 6.1$

$\begin{array}{lll}\text { Glaucoma } & 3 & 2.6\end{array}$

$\begin{array}{lll}\text { Cataract } & 89 & 77.4\end{array}$

I don't know $16 \quad 13.9$

What do infectious misdirected lashes indicate?

$\begin{array}{llr}\text { Cataract } & 3 & 2.6\end{array}$

$\begin{array}{lrr}\text { Trachoma } & 56 & 48.7\end{array}$

Conjunctivitis $\quad 30 \quad 26.1$

I don't know $25 \quad 21.7$

What are the risk factors for trachoma?

Unhygienic environment

$\begin{array}{lll}\text { Yes } & 78 & 67.8\end{array}$

$\begin{array}{lll}\text { No } & 36 & 31.3\end{array}$

$\begin{array}{lll}\text { Malnutrition } & 30 & 36.1\end{array}$

$\begin{array}{lll}\text { No } & 85 & 73.9\end{array}$

Which Food items contain Vitamin-A?

Green leafy vegetables, yellow

fruits

$101 \quad 87.8$

Cereals, rice, bread $\quad 5 \quad 4.3$

Others $\quad 4 \quad 3.5$

Don't know $4 \quad 3.5$

What is the age for cataract?

$\begin{array}{lll}\text { Old age individuals only } & 42 & 36.5\end{array}$

New borns only $\quad 63 \quad 55.3$

$\begin{array}{lll}\text { Other age group } & 9 & 7.9\end{array}$

How can diabetes be managed?

Diet

Yes $\quad 69 \quad 60$

$\begin{array}{lll}\text { No } & 46 & 40\end{array}$

Walking $\quad 50-5.5$

$\begin{array}{lll}\text { Yes } & 50 & 43.5 \\ \text { No } & 65 & 56.5\end{array}$

Medicines $\quad 56.5$

$\begin{array}{lll}\text { Yes } & 53 & 46.1\end{array}$

$\begin{array}{lll}\text { No } & 62 & 53.9\end{array}$

What are risk factors for Vitamin-A deficiency?

Pregnant women $\quad 35 \quad 30.4$

Children with measles and $\quad 40 \quad 35.1$

diarrhea $\quad 23-35.1$

$\begin{array}{lll}\text { Both of above factors } & 23 & 20.2 \\ \text { Others } & 16 & 13.9\end{array}$

How can you prevent Vitamin-A deficiency?

Maternal and child Vit-A

supplementation

$\begin{array}{lll}\text { Yes } & 81 & 70.4 \\ & 33 & 28.7\end{array}$ 
Measles vaccination

Yes

No

Balanced diet and clean water

Yes

No

What is the cause of night blindness

Mother is malnutritioned

Vitamin-A deficiency

Both above factors

Other factors

I don't know

What is treatment of conjunctivitis?

Medicine

Advise patient to maintain

hygiene

Refer to hospital/doctor

Both above along with refer

Is there any need of eye training for LHW?

Yes

No

How can we improve eye-care awareness?

Provision of medicines by

government

Yes

No

Provide eye training for LHW

Yes

No

Arrange awareness programs for public

Yes

No

Provision of balanced diet

Yes

No
13

101

44

70

3

35

79

30.4

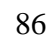

28

68.7

74.8

24.3

11.3

87.8

38.3

60.9

21.7

58.3

6.2

5.2

7.8

17.4

36.8

22.6

22.6

96.5

2.6

80

5

109
69.6

4.3 94.8
All questions of outcome were computed and then by using median ( $\mathrm{MD}=64)$, it was categorized into binary variable i.e. low awareness and high awareness.

Chi Square Test of association was conducted to check the association between outcome variable i.e. awareness and the independent variables i.e. age, educational level, experience, previous eye care training and currently how they are working (Table 3 ).

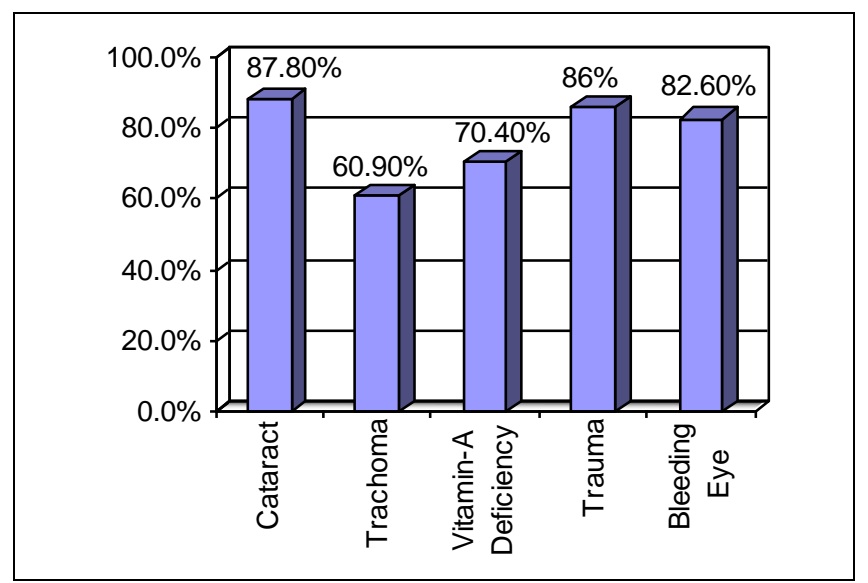

Graph 2: Diseases identified by PHCWs with correct treatment.

\section{Primary Eye Care Awareness of Primary Healthcare Workers}

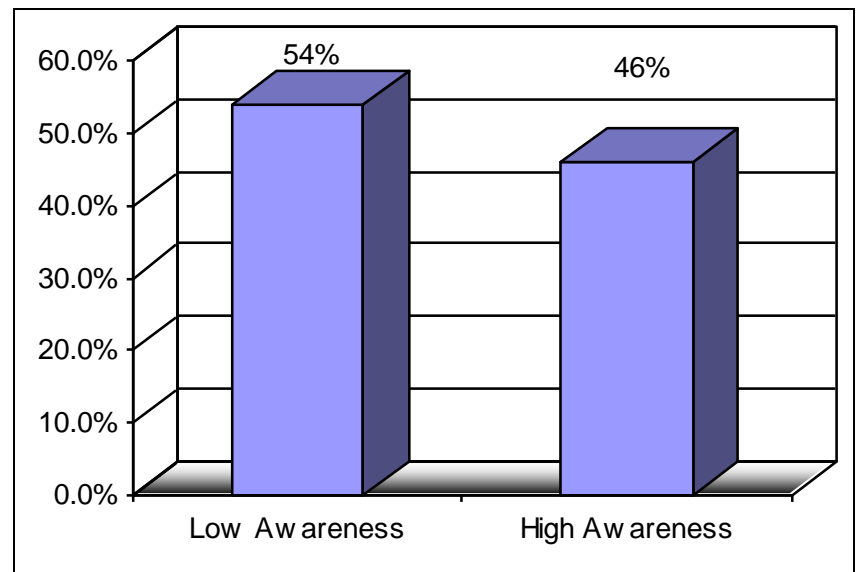

Graph 3: Primary eye care awareness of PHCW's

Table 3: Associated factors with awareness of PHCWs about Primary Eye Care.

\begin{tabular}{|c|c|c|c|c|c|}
\hline \multirow{2}{*}{ Variables } & & \multicolumn{2}{|c|}{ Awareness About Eye Care } & \multirow{2}{*}{$\begin{array}{c}\text { Chi-Square } \\
\text { (df) }\end{array}$} & \multirow{2}{*}{ p-value } \\
\hline & & Low & High & & \\
\hline \multirow{2}{*}{ Age (years) } & $\leq 44$ & $27(45 \%)$ & $33(55 \%)$ & \multirow{2}{*}{$4.01(1)$} & \multirow{2}{*}{0.045} \\
\hline & $>44$ & $35(63.6 \%)$ & $20(36.4 \%)$ & & \\
\hline \multirow{2}{*}{ Education (years) } & $\leq 10$ & $51(60 \%)$ & $34(40 \%)$ & \multirow{2}{*}{$4.86(1)$} & \multirow{2}{*}{0.028} \\
\hline & $>10$ & $11(36.7 \%)$ & $19(63.3 \%)$ & & \\
\hline \multirow{2}{*}{ Experience (years) } & $5-15$ & $26(55.3 \%)$ & $21(44.7 \%)$ & \multirow{2}{*}{$0.063(1)$} & \multirow{2}{*}{0.801} \\
\hline & $>15$ & $36(52.9 \%)$ & $32(47.1 \%)$ & & \\
\hline \multirow{2}{*}{ Designation } & LHS and LHV & $3(18.8 \%)$ & $13(81.2 \%)$ & \multirow{2}{*}{$9.25(1)$} & \multirow{2}{*}{0.002} \\
\hline & LHW & $59(59.6 \%)$ & $40(40.4 \%)$ & & \\
\hline Previous eye-care & Yes & $59(57.3 \%)$ & $44(42.7 \%)$ & 450 & 02 \\
\hline training & No & $3(25 \%)$ & $9(75 \%)$ & $4.50(1)$ & 0.3 \\
\hline No. of eye-care & Never & $3(30 \%)$ & $7(70 \%)$ & $8.84(4)$ & 0.065 \\
\hline
\end{tabular}




\begin{tabular}{|c|c|c|c|c|c|}
\hline \multirow[t]{3}{*}{ training } & Once & $9(42.9 \%)$ & $12(57.2 \%)$ & & \\
\hline & Twice & $25(71.4 \%)$ & $10(28.6 \%)$ & & \\
\hline & 3-4 times & $25(53.2 \%)$ & $22(46.8 \%)$ & & \\
\hline \multirow{3}{*}{$\begin{array}{l}\text { No. of eye patients } \\
\text { seen in a month }\end{array}$} & $1-5$ & $44(62.9 \%)$ & $26(37.1 \%)$ & & \\
\hline & $6-10$ & $11(37.1 \%)$ & $18(62.1 \%)$ & $5.56(3)$ & 0.135 \\
\hline & $11-15$ & $5(45.5 \%)$ & $6(54.5 \%)$ & & \\
\hline
\end{tabular}

\section{DISCUSSION}

A total of 115 PHCWs were included in the study, among them 99 were LHWs, 8 LHS and 8 LHVs. According to the present study, 54\% PHCWs had low awareness of PEC, although most of the PHCW's $(89.6 \%)$ had done previous training in primary eye care. The study established the significant relationship of level of awareness with the age, education and the job description of PHCWs. A previous study conducted in Southern Ethiopia showed that the knowledge about blinding eye disease did not significantly vary with the years of experience or previous healthcare training. ${ }^{7}$ Our study also showed non-significant association of level of awareness with years of experience or previous eye care training. This consistent finding emphasized need of the assessment of quality of eye care training being provided to healthcare workers. In a study conducted in India showed a remarkable improvement in knowledge among teachers after PEC training. ${ }^{9}$

Other studies in Pakistan showed that $35 \%$ of teachers in Rawalpindi had knowledge about eye conditions and $32.8 \%$ of general population in Azad Kashmir showed awareness about eye care services. ${ }^{10,11}$ Provision of PEC to the community is strongly associated with PHCWs particularly Lady Healthcare workers (LHWs). LHWs are given training for 15 months which include first 3 months of classroom training and 12 months on-the-job training about prevention and control of common illnesses. ${ }^{12}$ Pakistan is facing a double burden of disease (BoD), the burden is higher in the poor, and many of these can be controlled at relatively low cost interventions and best practices through primary and secondary care levels. ${ }^{13}$ A recent report of National Eye Health Committee indicates that Pakistan achieved a National Cataract Surgical Rate (CSR) of 5253 (with AJK included). ${ }^{14}$ A report on Rapid Assessment of Refractive Error in Children in Pakistan (2016-2017) by Brien Holden Vision Institute showed the prevalence of significant refractive error is $5.4 \%$ in the age of 5 to 15 years. ${ }^{15}$
Common diseases should be identified at the PHC. Concept of PEC and school health in India (2019) suggested that the trained teachers in schools could manage red eyes, loss of vision and pain in the eye by timely referral. ${ }^{16}$ In our study, majority of PHCWs (77.4\%) had awareness of white reflex of pupil and decreased vision in cataract. Previous studies also showed good knowledge about cataract i.e. $55.7 \%$ in Kenya and Malawi, ${ }^{17} 72.3 \%$ in Nigeria ${ }^{6}$ and $67.3 \%$ in Tanzania. ${ }^{18}$ Our research showed that $88 \%$ of PHCWs had knowledge of treatment options for cataract while previous studies showed this percentage to be $96.4 \%^{7}$ and $63.2 \% .^{18}$ This finding is also justifiable on the basis of high prevalence of cataract all over the world therefore; training regarding eye care is always focused on this disease.

Trachoma was identified by $48.7 \%$ of PHCWs and $60.9 \%$ considered that by improving environmental and personal hygiene trachoma can be cured similarly a study performed in Southern Ethiopia, ${ }^{7} 96 \%$ of health extension workers knew that trachoma could cause blindness and $13.5 \%$ considered face washing could eliminate the risk of trachoma. All the PHCWs had awareness of conjunctivitis being contagious. Among all the PHCWs $86 \%$ correctly identified the management of superficial foreign body similarly a previous study had $69.3 \%$ PHCWs who could manage this. ${ }^{18}$

Vitamin-A deficiency causes serious effects on eyes, majority of the PHCWs $(87.8 \%)$ correctly mentioned the food items that contained Vitamin-A. According to $70.4 \%$ PHCWs Vitamin-A deficiency could be prevented by providing Vitamin-A supplements to mothers and children. More than half of PHCWs $(58.3 \%)$ knew that Vitamin-A deficiency was the cause of night blindness among children. A study was conducted in Nigeria among PHCWs, stated that $28 \%$ of PHCWs correctly identified the common features of Vitamin-A deficiency. ${ }^{6}$ The dissimilarity between both studies can be due to demographic and contextual differences. Majority of the PHCWs $(92.2 \%)$ were aware of the fact that PEC was an essential part of PHC and $96.5 \%$ accepted that there 
was further need of providing PEC training to them. This finding proved the need of reinforcing primary eye care to make primary healthcare more useful for community. ${ }^{19}$

The low awareness of PEC among PHCWs shows that there is a need of providing primary eye care training to them with regular intervals of time. Awareness programs and eye-camps should be arranged for PHCWs. PHCWs being the frontline health workers should be equipped with adequate knowledge so that they can provide effective primary eye care to the community at the earliest time. The method of teaching and training PHCWs should involve the eye-models and colored pictures of diseases to make them visualize and understand the diseases in a better way. ${ }^{20}$

The limitations of this study was that it was conducted in a short period of time i.e. from October, 2019 to December, 2019. Only those PHCWs were included in the study that were available at the time of visit to BHUs. Majority of PHCWs were Lady Healthcare Workers (86\%), therefore the results cannot be generalized to all the Primary Healthcare Workers.

\section{CONCLUSION}

The study concluded that more than half of PHCWs had low awareness regarding PEC. All of them mentioned that there was a need of improving and refreshing their knowledge related to primary eye care. This can definitely reduce pressure on secondary and tertiary healthcare workers.

\section{Ethical Approval}

The study was approved by the Institutional review board/ Ethical review board. (PIO/TRG/19)

\section{Conflict of Interest}

Authors declared no conflict of interest.

\section{REFERENCES}

1. Courtright P, Seneadza A, Mathenge W, Eliah E, Lewallen S. Primary eye care in sub-Saharan African: do we have the evidence needed to scale up training and service delivery? Ann Trop Med Parasitol. 2010; 104 (5): 361-367.
2. What is Universal Eye Health? - IAPB Available from: https://www.iapb.org/advocacy/global-action-plan2014-2019/what-is-universal-eye-health/ Accessed on $25^{\text {th }}$ May 2020.

3. Minimum services delivery standards. available at: https://phc.org.pk/catI_HCE.aspx Accessed on $25^{\text {th }}$ May 2020.

4. Primary eye care framework. Clinical Council for Eye Health Commissioning 2018, Available at: http://www.ccehc.org.uk. Accessed on $25^{\text {th }}$ May 2020.

5. Etim BA, Ibanga AA, Udoh ME, Okonkwo SN, Agweye CT, Utam UA, et al. Eye Care Cadre Utilization and Knowledge about Eye Care Professionals among University Students in Calabar, Nigeria. J Adv Med Res. 2018; 28 (2): 1-6.

6. Abdulrahman AA, Rabiu MM, Alhassan MB. Knowledge and practice of primary eye care among primary healthcare workers in northern Nigeria. Trop Med Int Heal. 2015; 20 (6): 766-772.

7. Hailu Y, Tekilegiorgis A, Aga A. Know-how of primary eye care among Health Extension Workers (HEWs) in Southern Ethiopia. Ethiop J Heal Dev. 2009; 23 (2): 127-132.

8. Shrestha G, Sigdel R, Shrestha J, Sharma A, Shrestha R, Mishra S, et al. Awareness of eye health and diseases among the population of the hilly region of Nepal. J Ophthalmic Vis Res. 2018; 13 (4): 461.

9. Screening E, Dist I, Budh G, Agrawal D, Tyagi N, Nagesh SR. Awareness Levels of School Teachers Regarding Healthy Vision. Nat J Comm Med. 2020; 9 (8): 7-10.

10. Ahmad SS. Glaucoma suspect $\square$ : A Pratical Approach. Taiwan J Ophthalmol. 2017; 8: 53-55.

11. Ashraf F, Mobeen R. Status of awareness of optometry and primary eye care services among common population in district Bhimber, Azad Kashmir, Ophthalmol Pak. 2016; (04): 15-18.

12. Zhu N, Allen E, Kears A, Gaglia J, Atun R. Lady Health Workers in Pakistan Improving access to health care for rural women and families. 2014;11.

Available from: https://cdn2.sph.harvard.edu/wpcontent/uploads/sites/32/2014/09/HSPH-Pakistan5.pdf. Accessed on $25^{\text {th }}$ May 2020.

13. Ministry of Planning D \& reform. P. NATIONAL HEALTH VISION Pakistan 2016-2025. 2016; 3-17. Available from:

www.https://extranet.who.int/countryplanningcycles/sit es/default/files/planning_cycle_repository/pakistan/nati onal_health_vision_2016-25_30-08-2016.pdf. Accessed on 30 May 2020.

14. Bourne R, Dineen B, Jadoon Z, Lee PS, Khan A, Johnson GJ, et al. Outcomes of cataract surgery in Pakistan: results from The Pakistan National Blindness and Visual Impairment Survey. Br J Ophthalmol. 2007; 91 (4): 420-426. Doi: 10.1136/bjo.2006.106724. 
15. Yasmin S, Saifullah K, Minto H. Developing an integrated school eye health programme in Pakistan. Community eye Heal. 2017; 30 (98): S8-11.

16. Giri A, Behera S, Galhotra A. Concept of primary eye care \& school health in India. Indian J Community Fam Med. 2018; 4 (2): 55.

17. Kalua K, Gichangi M, Barassa E, Eliah E, Lewallen S, Courtright P. Skills of general health workers in primary eye care in Kenya, Malawi and Tanzania. Hum Resour Health, 2014; 12 (1): 4-9.

18. Byamukama E, Courtright P. Knowledge, skills, and productivity in primary eye care among health workers in Tanzania: Need for reassessment of expectations? Int Health, 2010; 2 (4): 247-252.

19. Sharon L, Lindner H, Mathews R, Morris S, Wells $\mathbf{L}$, Litt J, et al. What skills do primary health care professionals need to provide effective selfmanagement support $\square$ ? Seeking consumer perspectives. Aust J Prim Health, 2009; 15: 37-44.

20. Murthy GVS, Raman U. Perspectives on Primary Eye care. Comm Eye Health J. 2009; 22 (69): 10.

\section{Authors' Designation and Contribution}

Noor-ur-Rehman; Student: Concepts, Design, Literature search, Data acquisition, Manuscript preparation.

Hina Sharif; Senior Lecturer: Data analysis, Statistical analysis, Manuscript editing, Manuscript review.

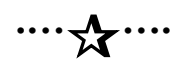

